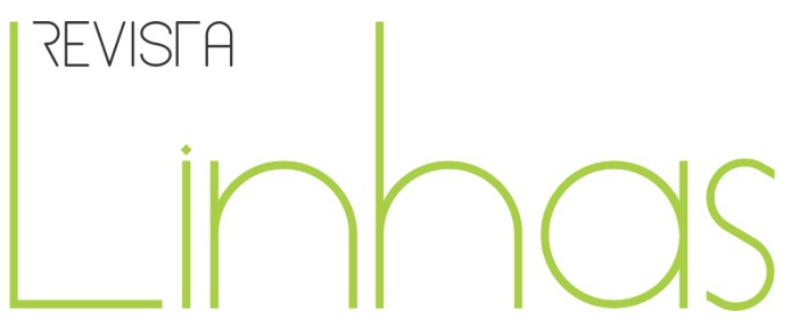

\title{
As novas tecnologias da informação e comunicação e a atividade experimental no ensino de ciências
}

\section{Resumo}

Este artigo tem como objetivo relatar um projeto de aprendizagem a partir das Novas Tecnologias da Informação e Comunicação, especificamente para a promoção do ensino de Ciências, em especial a atividade experimental. O referido projeto foi aplicado em uma turma de primeiro ano dos anos iniciais do Ensino Fundamental de uma escola pública estadual. A metodologia de pesquisa empregada foi inspirada no Estudo de Caso. A partir das novas tecnologias, foi possível criar múltiplas evidências, além de atividades diversificadas. Assim como outros recursos, o uso das novas tecnologias ligadas às atividades experimentais no ensino de Ciências podem ser usadas em diversas situações e com diferentes finalidades como motivação, despertar estímulos, possibilitar a prática, estabelecer a sucessão de aprendizagens entre outros.

Palavras-chave: Ciências; Estudo e Ensino; Ciências e Tecnologia.

\section{Ruhena Kelber Abrão}

Doutorando em Educação em

Ciências pela Universidade

Federal do Rio Grande do Sul UFRGS - Brasil

kelberabrao@gmail.com

\section{Diana Francisca Adamatti}

Doutora em Engenharia Elétrica pela Escola Politécnica da Universidade de São Paulo EPUSP - Brasil dianaada@gmail.com

\section{Para citar este artigo:}

ABRÃO, Ruhena Kelber; ADAMATTI, Diana Francisca. As novas tecnologias da informação e comunicação e a atividade experimental no ensino de ciências. Revista Linhas. Florianópolis, v. 16, n. 31, p. $305-324$, maio/ago. 2015. 


\title{
The new information and communication technologies and experimental activity in science education
}

\begin{abstract}
This paper to present a project learning from the New Technologies of Information and Communication, specifically to promote the teaching of Science, especially the experimental activity. This project was implemented in a class of first year in the early years of elementary school in a public school. The research methodology employed was inspired by the Case Study. As new technologies could create multiple evidence, and diversified activities. Like other resources, the use of new technologies related to the experimental activities in science teaching can be used in different situations and for different purposes such as motivation, arousal stimuli, enabling the practice to establish the sequence of learning among others.
\end{abstract}

Keywords: Science; Study and Teaching; Science and Technology. 


\section{Introdução}

A sociedade atual tem como elemento relevante a presença cada vez mais acentuada da ciência e da tecnologia envoltas ao cotidiano da população, em decorrência do avanço quase desenfreado dos meios de informação e comunicação e pela grande produção de conhecimentos científicos e de inovações tecnológicas. Tal fato torna urgente a estruturação de processos que visem à apropriação de conhecimento científico e tecnológico por toda a sociedade, de forma a instrumentalizá-la para a formação de opinião e para a ação fundamentada. Neste sentido, o ensino de Ciências na escola é de vital importância e pode ter seus resultados potencializados se ampliar sua ação já nos primeiros anos do Ensino Fundamental.

No presente artigo, apresentam-se alguns elementos resultantes de um projeto de aprendizagem desenvolvido durante o ano de 2011, junto a alunos dos anos iniciais do Ensino Fundamental de uma escola pública estadual da cidade de Rio Grande/RS. A motivação para tal estudo nasce da dificuldade que o autor demonstrava para ministrar a disciplina de Ciências Naturais quando lecionava aulas nos anos iniciais do Ensino Fundamental, em que faltava, muitas vezes, algum recurso didático para demonstrar de forma mais nítida os conteúdos abordados na disciplina supracitada utilizando o laboratório de informática, o qual é pouco utilizado por grande parte dos professores.

A atividade realizada buscou, entre outras coisas, atuar sobre o ensino na disciplina de Ciências, fazendo uso da experimentação através das Novas Tecnologias da Informação e Comunicação como metodologia para trabalhar conteúdos de Física com as crianças, pois, muitas vezes, grande parte dos pedagogos tem receio de fazê-lo.

O projeto desenvolvido surgiu como tentativa de colaborar na superação do quadro verificado pelos exames de avaliação da educação no Brasil, tanto dos exames de caráter nacional quanto dos exames de cunho internacional como o Programme for International Student Assessment (PISA) que é um programa de avaliação educacional proposto aos estudantes de 15 anos de idade (idade a qual se pressupõe o término da escolaridade básica obrigatória na maioria dos países). No Brasil, o PISA é coordenado pelo Instituto Nacional de Estudos e Pesquisas Educacionais Anísio Teixeira (INEP). O 
teste é estruturado em três áreas: Leitura, Matemática e Ciências. Em cada edição, de três em três anos, a prova tem uma ênfase maior em uma dessas três áreas.

A partir disso, cada vez mais o número de participantes que fazem a prova têm aumentado, bem como o desempenho nas provas tem crescido em todas as áreas.

\begin{tabular}{|c|c|c|c|c|c|c|c|}
\hline & $\begin{array}{l}\text { PISA } \\
\end{array}$ & Diferença & $\begin{array}{l}\text { PISA } \\
\end{array}$ & Diferença & $\begin{array}{l}\text { PISA } \\
\end{array}$ & Diferença & PISA \\
\hline Pontuação & 2000 & $2000-2003$ & 2003 & $2003-2006$ & 2006 & 2006-2009 & 2009 \\
\hline LEITURA & 396 & +7 & 403 & +10 & 393 & +9 & 412 \\
\hline MATEMÁTICA & 334 & +22 & 356 & +14 & 370 & +16 & 386 \\
\hline CIÊNCIAS & 375 & +15 & 390 & ZERO & 390 & +15 & 405 \\
\hline
\end{tabular}

Sendo assim, entende-se que área de Ensino das Ciências é um campo de conhecimento que carece de investigação, tendo em vista que produz diferenças nos indicadores do Censo Educacional e no desempenho de estudantes de escolas públicas em relação às privadas e dentro da própria rede pública, entre escolas estaduais e municipais. Igualmente, ele engloba diferentes abordagens que serão, nos anos seguintes de escolarização, fragmentadas em áreas tais como a Física, Química e Biologia. No entanto, o crescimento do número de pontos nas provas de Ciências não tem aumentado na mesma proporção da prova de Leitura e Matemática. O índice de pontos em Ciências manteve-se o mesmo entre os anos de 2003-2006. Já entre os anos 2000-2003 e 20062009, ficou nos 15 pontos. Se Compararmos Leitura, Matemática e Ciências, a Matemática teve os maiores índices de progressão, ao passo que a Leitura teve os menores, porém o seu índice inicial é superior aos demais. Sendo assim, o escore da prova de Ciências no Brasil, segundo o PISA, é menor do que o de países subdesenvolvidos, como Qatar, Peru, etc. (OCDE, 2010). A partir disso, ainda que se tenha noção de Ciências no campo da Física, da Biologia e da Química, a avaliação do PISA se encontra sob a perspectiva de três grandes áreas de aplicação: Ciências da vida e da saúde, Ciências da terra e do meio ambiente e Ciência e tecnologia.

Desta forma, foram ofertadas aos alunos dessa escola oficinas de experimentação em Ciências a partir dos Objetos Virtuais de aprendizagem que, segundo Spinelli, não são apenas a simulação de um experimento real, mas sim uma situação, uma história, na qual 
o educando percorre algumas etapas, envolvido por um contexto que exige a compreensão de determinados conceitos científicos. Assim, a procedência e o sucesso da atividade devem ser avaliados sob dois olhares distintos: o primeiro deles, sob o ponto de vista de quem o projeta; o segundo, sob o ponto de vista de quem o utiliza (SPINELLI, 2009, p. 8). A perspectiva de trabalho assumida nas oficinas buscou romper com a sistemática que considera demasiadamente "complicado" trabalhar experimentos de Física com crianças. Tentou romper também com a imagem negativa que muitas crianças tinham relativamente às aulas de Ciências, imagem esta que poderia influenciar nas suas decisões futuras em relação à aprendizagem nesta área de saber.

\section{Ensino, Ciência e Tecnologia}

Existe uma crítica constante dirigida ao ensino de Ciências nas escolas, referindose a ausência de experimentação nas aulas dessa disciplina. Por trás de um amplo espectro de argumentos que costumam ser levados em conta defendendo o ensino experimental, encontra-se o pressuposto de que a experimentação contribui para uma melhor qualidade do ensino.

Grande parte das vezes, crianças e jovens levam vantagem quando se trata de incorporar e dominar o uso das novas tecnologias. Geralmente, a criança experimenta estas atividades até dominá-las. O resultado pode ser verificado nos mais diversos ambientes, casa, escola ou em outros espaços. Após decifrar o funcionamento daquele mecanismo, o sujeito passa a testá-lo de todas as formas possíveis. Levando isso para a escola, verifica-se o descompasso que existia entre o modelo tradicional de ensino, fortemente apoiado na figura do professor e na transmissão de conhecimentos, centrado na memorização e reprodução, e o modelo pós-piagetiano, que enfatiza a participação colaborativa, dialógica, ampliada pela cibercultura. Os estímulos atrativos das novas tecnologias concorrem diariamente com a rotina da maioria das escolas. O resultado de tal disputa é a sala de aula cada vez menos atraente, com alunos cada vez mais desinteressados no que ela propõe. Os alunos da era tecnológica demandam da escola um novo espaço de aprendizagem, semelhante aos proporcionados pelas novas 
tecnologias, em que possam interferir, modificar, produzir, em uma atitude cada vez menos passiva e mais ativa em seu próprio conhecimento. O uso de recursos didáticos inovadores se constitui como uma alternativa que pode contribuir para o aumento de interesse dos alunos pela disciplina, possibilitando a construção do conhecimento de forma mais dinâmica, interativa e não linear (CORRÊA; FERREIRA, 2008). No ensino de Ciência, a tecnologia é um fator primordial e as novas tecnologias oferecem inúmeras possibilidades para que os estudantes se envolvam nas chamadas atividades práticas, atividades experimentais, experiências, experimentos, entre outros termos semelhantes ligados ao fato de tentar manipular a construção de um material, favorecendo a investigação em nível fenomenológico e técnico, das ações de fazer e testar este, incitando o sujeito a questionar e investigar os princípios, bem como conceitos envolvidos no experimento, atribuindo assim um significado pessoal a esses conceitos, trazendo significação para os mesmo (COELHO et al., 2008).

Em geral, essas atividades têm como principal característica o caráter predominantemente prático em comparação com outras atividades que exploram apenas os aspectos teóricos da Ciência. Essa pluralidade de nomenclaturas ligadas à experimentação também é comum em revistas e artigos científicos ou de divulgação de Ciências. No entanto, há uma tendência na área científica a padronizar a nomenclatura corrente, o que favorece a comunicação e evita equívocos.

A natureza do trabalho que se realiza nas escolas de Ensino Fundamental tem um caráter pedagógico distinto dos trabalhos de investigação científica que ocorrem em centros de Ensino Superior e em outros setores da sociedade. Fator este que não tira destas escolas o valor intrínseco das atividades nas quais os alunos podem desenvolver uma série de habilidades ligadas à ação-reflexão.

Existem estudos como os de GABEL (1993), que fundamentam a importância da atividade prática na formação científica. Alguns países, como Portugal, estabeleceram um percentual de atividades práticas que devem estar presentes no currículo de ciências (30\%). Apesar de não existir uma orientação específica dos formuladores de currículos nacionais a esse respeito, os professores têm à disposição muitos livros didáticos que propõem a realização de atividades práticas, desde a Educação Infantil, passando pelos anos iniciais e finais do Ensino Fundamental e Médio, variando os graus de complexidade. 
Baseado nos estudos de Trowbridge e Bybee (1990 apud Valadares, 2009), tradicionalmente, pelo menos cinco objetivos têm sido atribuídos ao ensino experimental: aprender a respeito da natureza da ciência e da tecnologia; adquirir habilidades ou instrumentos cognitivos relacionados aos processos; aprender habilidades manipulativas: aprender os principais conceitos e princípios científicos; desenvolver interesses, atitudes e valores. Ainda segundo estes autores, as atividades experimentais propiciam o desenvolvimento de diversas capacidades, entre elas: Capacidades aquisitivas: ouvir, observar, pesquisar, inquirir, investigar, recolher dados; Capacidades organizacionais: registrar, comparar, constatar, classificar, organizar, planificar, rever, avaliar, analisar; Capacidades criativas: desenvolver planos, arquitetar, inventar, sintetizar; Capacidades manipulativas: Usar instrumentos, cuidar dos instrumentos, demonstrar, experimentar, reparar, construir, calibrar; Capacidades de comunicação: questionar, discutir, explicar, relatar, escrever, criticar, construir gráficos, ensinar (VALADARES, 2009, p.78). Além do desenvolvimento dessas capacidades cognitivas, também ocorre o desenvolvimento das capacidades afetiva, emocional e social inerentes aos trabalhos em grupo. Quando bem concebidas e exploradas, essas atividades preparam os alunos para a vida social.

O impacto que ciência e tecnologia provocam hoje na sociedade requer que a formação escolar ocorra num contexto prático e numa perspectiva de interação da ciência, tecnologia, sociedade e ambiente. A fundamentação teórica para defender um equilíbrio entre os componentes teóricos e práticos do ensino de Ciências pode ser buscada, inicialmente, em Piaget. Este foi um defensor da ciência como construção humana, sempre desafiante e sempre inacabada. Seus estudos e publicações criticavam o pouco interesse, manifestado em currículos da época, pelas atividades experimentais e fundamentou a importância do ensino prático para o desenvolvimento da criança. Segundo Piaget, a experiência, entendida como resultado da atividade experimental, é útil para desenvolver as funções de conhecimento, as funções de representação e as funções afetivas, igualmente fundamentais ao desenvolvimento (COLL, 1994). Em suas descrições dos estágios de desenvolvimento, Piaget estabelece que, por volta dos sete anos, a criança atinge o estágio das operações concretas, em que ainda é decisivo manipular objetos concretos do mundo real, familiarizando-se com eles. Nesse estágio, a 
experimentação é fundamental. No entanto, um trabalho experimental que exija raciocínio hipotético dedutivo e o controle de variáveis ainda é desaconselhável nessa etapa, pois tal desenvolvimento só ocorrerá em torno dos 12 anos (COLL, 1994).

Nos anos iniciais do Ensino Fundamental, o professor conta com um elemento primordial como aliado, a curiosidade infantil; curiosidade sobre o mundo que a cerca, sobre o qual ela não se cansa de perguntar. As crianças, na maioria das vezes, possuem uma boa disposição para "a aventura de conhecer", para a preparação de experimentos para ver "o que acontece" ou "como é que fica se eu fizer isso". Propor as situações de aprendizagem de maneira que os alunos passem a ter questionamentos, se arrisquem a prever acontecimentos e proponham estratégias para encontrar soluções é a porta de entrada para as atividades bem-sucedidas (CARVALHO, et al., 1998).

De modo geral, os principais argumentos ligados à dificuldade e até à impossibilidade de implementação de uma abordagem experimental no ensino de Ciências são a falta de instalações adequadas, a escassez de equipamentos e outros materiais, o excessivo número de alunos em classe e as deficiências na formação de professores. No entanto, mesmo em escolas onde essas dificuldades inexistem, o ensino experimental ainda não foi incorporado aos processos de aprendizagem. Isso sugere que não basta ter as condições materiais, é necessária uma mudança de mentalidade que pressuponha uma nova forma de conceber o papel da experiência na aquisição de conhecimentos. Segundo Carvalho (1992), o número e o tipo de atividades práticas sugeridas nos livros didáticos são bem variados. As atividades que podem ser realizadas pelo professor, como demonstração, geralmente possuem um roteiro mais ou menos detalhado e previamente elaborado, a serem realizadas antes das aulas teóricas, visando a introduzir e explorar os temas ou depois, para simples verificação do que foi exposto; e aquelas que podem ter um caráter indutivo, em que os estudantes podem controlar variáveis e descobrir ou redescobrir relações funcionais entre essas variáveis; ou ainda dedutivo, quando eles têm a oportunidade de testar certas predições de teoria. Entretanto, nem todas essas maneiras de realizar um trabalho prático produzirão os mesmo resultados de aprendizagem. Segundo Piaget (1995): 
Uma experiência que não seja realizada pela própria pessoa, com plena liberdade de iniciativa, deixa de ser, por definição, uma experiência, transformando-se em simples adestramento, destituído de valor formador por falta da compreensão suficiente dos pormenores das etapas sucessivas. (PIAGET, 1995, p. 78)

A partir desse fragmento, um experimento no qual o aluno é apenas espectador, ou aquele em que ele segue um roteiro previamente estabelecido, sem ter participado de nenhuma de suas etapas como identificação do problema, levantamento e verificação de hipóteses, observação, coleta de dados, discussão, entre outros, não cumprirá sua função formadora. Nas aulas de Ciências, apesar da complexidade e da artificialidade das relações que se estabelecem, bem como das condições de aprendizagem dos alunos e das características das ações pedagógicas, surgem, frequentemente, situações nas quais este modelo, de confrontar hipóteses com a evidência experimental, poderia ser ensaiado.

As observações de Piaget sobre o desenvolvimento mental revelam que, na idade escolar, o raciocínio das crianças resume-se ,preponderantemente, a operar sobre objetos e situações com um significado concreto. Neste caso, observar, pensar e agir seriam processos que deveriam caracterizar a atividade da criança. Um método sugerido para desencadear tais processos é o método da descoberta (COLL, 1994). Esta ideia costuma ser recomendada como fio condutor da prática docente. No entanto, em grande parte das vezes, reduzida à receita de possibilitar o uso das novas tecnologias às crianças e deixar que elas descubram por si próprias o conhecimento científico. Nesse contexto, a descoberta é entendida como um processo através do qual os princípios científicos são revelados infalivelmente por um método indutivo, que opera sobre os fatos observados, quando deveria ser entendido como a aprendizagem que resulta de uma situação programada para equilibradamente propiciar, através do diálogo professor/aluno a internalização do significado de um fenômeno em seu contexto real (MOREIRA, 1995). 


\section{Procedimentos metodológicos}

A Lei de Diretrizes e Bases (LDB), Lei n 9.394, de 1996 (BRASIL, 1996), estabelece, no que tange à educação básica, compreendida pela Educação Infantil, Ensino Fundamental e Ensino Médio, “desenvolver o educando, assegurando-lhe a formação indispensável para o exercício da cidadania e fornecer-lhe meios para progredir no trabalho e em estudos posteriores" (MEC/SEF, 1998). Com base nessa prerrogativa, o ensino no Brasil tem por objetivo a formação básica do cidadão mediante alguns parâmetros, como os supracitados. No contexto das tecnologias da informação e comunicação na educação, há um enfoque da LDB para a tecnologia aplicada a projetos, dando liberdade e estimulando os estudantes a criar, recriar, e partir para novas experiências educacionais. Porém, ainda percebe-se na escola um direcionamento sedimentado para o trabalho puramente disciplinar, no currículo escolar, no qual o enfoque técnico do conhecimento é visto como prioridade. A descontextualização, bem como a falta de significação do conteúdo trabalhado, dificultam o entendimento pelo aluno. Consequentemente, a construção do conhecimento, assim como a relação entre os saberes, as conexões entre o estudado e o vivido não se estabelecem, comprometendo sua construção. São raros os momentos em que são estimulados o desenvolvimento de habilidades e a formação de atitudes e valores, já que a preocupação maior é com o desenvolvimento dos conteúdos programáticos de cada disciplina, independentemente de que o aluno esteja aprendendo ou não, de que ele esteja conseguindo ou não estabelecer relações entre o que está sendo ensinado e a realidade mais ampla.

Desta forma, a fim de melhor compreender o contexto escolar, limitando-se, nesta análise, ao primeiro ano do Ensino Fundamental e à verificação de como é trabalhado o Ensino de Ciências nos anos iniciais do Ensino Fundamental associado às Novas Tecnologias da Informação e Comunicação, optou-se por uma pesquisa qualitativa. Por base no problema Como promover a aprendizagem experimental das Ciências Naturais nos anos iniciais a partir das Novas Tecnologias da Informação e Comunicação (NTIC), foi elaborado um projeto de aprendizagem visando o ensino de Ciências. A metodologia empregada foi inspirada no Estudo de Caso. Optou-se por esse tipo de pesquisa, pois ela permite uma maior profundidade sobre o tema a ser abordado, além de possibilitar o uso 
de múltiplas fontes de evidências (YIN, 2001). Como se investigou o uso das NTIC, tratouse de uma análise contemporânea. A unidade de caso constitui-se de uma turma de primeiro ano, do turno da manhã, de uma escola pública estadual do Rio Grande/RS.

Normalmente, os Estudos de Caso configuram-se como uma metodologia que se vale de múltiplas fontes de evidência, pois permitem o desenvolvimento da investigação em várias frentes em relação ao mesmo fenômeno. Nesse sentido, baseado em Yin (2001), utilizou-se as seguintes fontes de evidência: Observação do tipo direta, que consiste em dar ao pesquisador a oportunidade de registrar os acontecimentos em tempo real; Entrevistas do tipo abertas e semiestruturadas que, segundo o autor, constituem-se como a principal fonte de evidências em um Estudo de Caso; Análise Documental, na qual o ponto de partida não deve ser a análise de um documento, mas a formulação de um questionamento, bem como a problematização das fontes que são interpretadas como testemunhas, vestígios de um recorte na história. Para esta, foram feitas fotocópias do currículo escolar, do regimento e do Projeto Pedagógico, para poder identificar como a escola legalmente diz se organizar em relação à Educação Infantil e ao primeiro ano.

Os objetivos foram mapear o ensino de Ciências no primeiro ano, através do acompanhamento do mesmo grupo de alunos de forma não interventiva, registrando os acontecimentos na sala de aula no período de agosto a setembro de 2011, utilizando-se o plano de ensino da disciplina. Levou-se em conta a descrição dos sujeitos envolvidos, suas exterioridades e singularidades; utilizar alguns Objetos Virtuais de Aprendizagem (OVA) para a promoção de atividade experimental de Ciências. Após o período de observações, foram realizadas 4 oficinas, com uma hora de duração cada, utilizando-se alguns OVA do repositório de objetos educacionais do Ministério da Educação ${ }^{1}$ específicos para os anos iniciais. Atualmente, este repositório digital, especificamente na área de Ciências, possui: 33 OVA contendo animações e simulações; 27 de áudio; 7 de experimentos práticos; 28 de hipertextos; 24 imagens; 1 mapa; 11 softwares educacionais; e 59 vídeos.

Foram observados semanalmente, dois períodos de aula, especificamente, no momento em que a professora ministra os conteúdos ligados às Ciências Naturais, o que perfaz um total de 6 horas de observação. Os registros das observações foram realizados

\footnotetext{
${ }^{1}$ Disponível em http://objetoseducacionais2.mec.gov.br/
} 
de forma descritiva, sendo selecionados apenas os episódios pertinentes à proposta de pesquisa. Após o período de observações, foram aplicadas 4 horas de oficinais práticas que tiveram por base o projeto de aprendizagem “Da Terra ao espaço”, que será explicado mais adiante.

\section{Análise de dados}

A primeira etapa do projeto consistiu em mapear o ensino de Ciências no primeiro ano. Para isso, foram observadas 6 horas das aulas de Ciências. A partir das observações e entrevistas com a professora da turma, foi possível identificar que esta disciplina tem como premissa, de acordo com o Projeto pedagógico da escola, trabalhar o Ciclo de vida e sentidos envolvendo noções sobre meio ambiente e o corpo humano, possibilitando uma maior compreensão da criança a respeito do mundo que a cerca e sobre si mesma; Animais mamíferos e terrestres, trabalhando noções de respeito à diversidade de seres vivos e sua importância para os ambientes naturais, desenvolvendo critérios que possibilitem agrupar e distinguir grupos de seres vivos a partir da observação e da comparação das características destes; Corpo humano, desenvolvimento de noções básicas de saúde e cuidados com o corpo; e Meio ambiente, no qual trabalham-se noções e ideias que permitam o desenvolvimento de uma postura de respeito em relação ao meio ambiente.

Segundo relato, a própria professora crê na dificuldade de ministrar o conteúdo relacionado às Ciências: "A disciplina de Ciências é importante, mas mais importante é o aluno ler e escrever. A minha prioridade é a leitura, a escrita e os números."

Questionada sobre o modelo tradicional de ensino, baseado na exposição, cópia e reprodução do livro didático a docente relata:

"É difícil achar o material sem ser o livro didático. Nem sempre a gente sabe a matéria, não tivemos formação para isso. Um dia eu estava tentando fazer uma experiência do livro: Afunda ou não afunda. $O$ experimento consistia em colocar um ovo na água com e sem sal, no qual um afundava e o outro não. Um aluno me perguntou porque isso acontecia, ao usar a explicação do livro (a que eu sabia), outro 
questionou dando outra explicação. Ao questioná-lo, perguntei em que lugar havia aprendido aquilo ele disse no "O Mundo de Beekmam" e eu nem sei o que é isso, mas confirmei o que ele disse."

A partir das observações, os autores pensaram em um projeto de aprendizagem que abrangesse os quatro eixos trabalhados na disciplina, criando-se assim o projeto: $\mathrm{Da}$ terra ao espaço. Para a realização das oficinas do projeto, foram utilizados alguns programas tutoriais que são entendidos por Levy (2007) como uma ferramenta de ensino/aprendizagem que pode, conter ou não, imagens, e/ou textos explicativos com o passo-a-passo do funcionamento de um mecanismo, além de alguns Objetos Virtuais de Aprendizagem (OVA) que, para este mesmo autor, organizam o conhecimento de uma área específica fazendo com que o aluno passe a interagir com os textos do objeto escolhido para estudo por meio de recursos da tecnologia informática destacando-se a utilização de sons, imagens, vídeos e outros efeitos especiais, bem como os recursos providos pela organização hipertextual dos textos. Ao passo que o aluno vai interagindo com o conhecimento organizado, vai fazendo exercícios que, normalmente, são utilizados para a fixação do conteúdo. A utilização dos OVA prevê uma certa facilidade de socialização do sujeito com o objeto, pois cada aluno pode conduzir o seu processo de interação no tempo assíncrono.

Foram utilizados quatro OVA da gama de animações e simulações. Sendo o primeiro o "Terrário", cujo objetivo é estimular o aluno a desenvolver experimentos práticos relacionados ao meio ambiente, abordando temas como o ciclo da água, tipos de solo e fotossíntese. O objeto virtual de aprendizagem em questão é um experimento prático que demonstra, passo-a-passo, a construção de um terrário de baixo custo. Por caracterizar-se como uma atividade de cunho prático, as crianças, através da manipulação do material, puderam montar, bem como acompanhar, a rotina do terrário em sala de aula onde permaneceu por mais de um mês.

Conforme relato, embora a criação de um terrário seja algo simples nos anos iniciais, a professora relata que também faz algumas experiências de simulação, sendo o

\footnotetext{
${ }^{2}$ Programa estadunidense da década de 90, no qual eram realizados experimentos a partir de cartas de crianças, podendo estes serem reproduzidos, na maior parte das vezes, por elas.
} 
plantio do feijão uma delas. Não é difícil de ver esta prática sendo aplicada nos anos iniciais. ABRÃO (2011, p. 79), destaca que

Algumas atividades são rotineiras durante a semana, como modelagem, música, livros, vídeos, desenho, colagem, recorte, pinturas a dedo entre outras. O plantio de sementes em copos plásticos também era uma atividade presente, conforme relato:

Observação do pé de feijão

Dia 26/10/09 - Segunda-feira: Plantamos feijões utilizando algodão, pote plástico, grãos de feijão e água.

Dia 27/10/09 - Terça-feira: os feijões estão ficando inchados. Hoje não regamos.

Dia 28/10/09 - Quarta-feira: os feijões estão começando a abrir. Hoje também não regamos.

Dia 29/10/09 - Quinta-feira: os feijões começaram a brotar e as raízes a aparecer.

Dia 30/10/09 - Sexta-feira: os feijões não cresceram quase nada. Botamos água hoje.

Dia 03/11/09 - Terça-feira: se passaram três dias (sábado, domingo e segunda). Hoje os feijões estão crescidos, regamos.

Dia 04/11/09 - Quarta-feira: O pé de feijão continua crescendo...

Todo este processo foi acompanhado com seriedade pelas crianças, que se sentiam responsáveis pelo pé de feijão. Durante a semana do pé de feijão, a professora aproveitou para contar a história de "João e o pé de feijão", o que provocou expectativa de algumas crianças, que acreditavam que o pé de feijão cresceria até o céu.

Nesse sentido a professora relata:

Todos os anos eu faço aquela do feijão do algodão. Tu sabe qual é, né? Os alunos amam ver e acompanhar a flor crescer, faço até um diário do pé de feijão. As crianças esperam ansiosas as flores crescerem, com isso já faço uma associação com o meio ambiente.

O segundo OVA utilizado foi “O Ciclo da água”. Este é classificado como programa de exercício e prática que pode ser comparado aos tradicionais cadernos e lista de exercícios, muito utilizados no processo de ensino e de aprendizagem das mais diversas áreas de conhecimento. Nesse modelo, os alunos fazem os exercícios, normalmente, 
sobre um conhecimento trabalhado e discutido em sala de aula, utilizando-se dos recursos do computador. Por se tratar de um processo multimídia, envolve música, imagens entre outros e a interação é mais evidente, tornando a atividade, na maioria das vezes, mais agradável.

Tal afirmação pode se ratificar a partir do seguinte fragmento:

- Olha Tia, a água faz tudo isso mesmo?

- Sim, J.C. nós vimos isso em sala, lembra?

- Mas não sabia que era assim.

- Então era como? É desse jeito mesmo que nem eu falei.

- Ah tia, mas assim eu curti ${ }^{3}$ mais.

A partir desse excerto, a professora demonstrou um pouco de chateação, pois, a princípio poderia parecer que ela não ministrou aquele conteúdo ou que ele fora dado de forma aleatória. Após a realização dos exercícios, a correção das atividades ocorre de forma simples, pois as mesmas são em grade, automáticas. O professor pode acompanhar o resultado da atividade dos alunos por meio de relatórios emitidos pelo programa. Geralmente, os exercícios são de múltipla escolha ou com respostas únicas e diretas, principalmente para diminuir o grau de complexidade na correção. Porém, nem sempre esses resultados têm valor pedagógico satisfatório, pois se detecta o erro e não o motivo pelo qual o aluno não chegou à resposta desejada, fato este criticado pela professora.

Este material permite ao aluno perceber a importância de utilizar, de forma consciente, a água em sua casa, deixando claro que as práticas de economia contribuem para a maior durabilidade deste recurso limitável. O material apresenta um quadro com as principais atividades responsáveis pelo consumo de água em uma residência e, ao passar o mouse sob cada uma delas, são exibidas dicas de como reduzir gastos, bem como aproveitar da melhor forma a água e os benefícios que ela oferece.

Após a atividade, a professora, questionando-se para saber se os alunos conseguiram ou não assimilar os conteúdos a respeito do ciclo da água, sugere: Acho que

\footnotetext{
${ }^{3}$ Nesse momento o aluno faz um sinal com a mão direita, mais precisamente com o polegar, imitando o símbolo curtir, algo característico do Facebook, um mecanismo de rede social.
} 
se você criasse um roteiro de perguntas para orientar as crianças elas sentiriam menos dificuldades e aprenderiam mais."

A partir deste trecho, a professora crê que o processo de aprendizagem das crianças ocorre por repetição. Quanto maior o número de exercícios, mais efetiva será a aprendizagem. Como o OVA utilizado não trabalhava nessa ótica, ela deduz que não houve aprendizagem.

O terceiro OVA utilizado foi sobre a "Reciclagem". Este se encaixa no modelo de jogos educacionais, por fazerem parte de um dos principais grupos de aplicativos utilizados no ambiente doméstico. Os jogos educacionais são softwares que têm uma boa aceitação junto aos alunos, principalmente em função de suas características lúdicas. Esses aplicativos normalmente são utilizados para desenvolver habilidades de aplicação dos conhecimentos dos alunos, por meio do seu envolvimento com o ambiente do jogo. Contudo, muitos pais e professores não enxergam a validade pedagógica dessa modalidade de software, pois acham que o aluno está somente brincando. O objetivo desse OVA é fazer com que o aluno aprenda sobre a separação do lixo de acordo com os materiais (plástico, metal, papel, vidro e orgânico). Nesse objeto virtual existe um caráter competitivo, pois quanto menor for o tempo que a criança levar para separar o lixo, mais pontos ela ganhará.

O último OVA utilizado foi o "Sistema Solar". Este se encaixa no tipo de OVA existente na categoria programas de simulação. Tal aplicativo tem a função de possibilitar a interação do aluno com fenômenos do mundo real que dificilmente poderiam ser experimentados em uma relação direta, como o estudo de furacões, de tempestades, de erupções vulcânicas, de reações químicas de elementos radioativos, entre outros. Outra característica desses recursos tecnológicos é a facilidade que o aluno tem de mudar uma determinada situação, sem causar risco para si ou para o outro, como a aplicação de uma determinada hipótese que causaria sérios problemas fora do ambiente de simulação.

Apesar de possuir uma filosofia pedagógica bastante interessante, esses softwares nem sempre conseguem atingir qualidade satisfatória. Tal fato acontece, principalmente, devido a dois problemas do processo de construção desse tipo de aplicativo: dificuldade de programação de modelos de fenômenos complexos e as limitações dos sistemas 
computacionais disponíveis nas instituições de ensino ou no lar dos estudantes, pois um software de simulação mais sofisticado exige grandes recursos computacionais (MEDEIROS e MEDEIROS, 2002).

Tão logo esta atividade se encerrou a professora relata:

Estou muito feliz que os alunos puderam utilizar o laboratório de informática de outra forma que não para brincar. Elas são muito carentes e quando têm acesso ao computador, é para brincar. Poucas vezes têm a possibilidade de uma atividade de conhecimento que trabalha divertimento e brincadeira. Jamais seria possível explicar astronomia de maneira tão clara e eficiente. Dá para ver nos olhos das crianças como elas amaram esta atividade.

Por meio de simulações digitais, o homem é capaz de criar situações virtuais que podem ser atualizadas e, assim, visualizar características de uma nova realidade, fato este decisivo na escolha do simulador do Sistema Solar que objetiva fazer com que o aluno entenda a sequência dos planetas no sistema solar. Ao encaixarem os planetas, os mesmos percorrem a órbita da terra de maneira proporcional à realidade. Ao clicar em cada um deles, são informados alguns dados como graus Celsius, números de luas, tipo de superfície entre outros. Sem dúvida, as crianças sentem-se mais motivadas com o conteúdo ligado à astronomia, pois as remete ao espaço, foguetes, planetas, elementos estes que estão fora do dia-a-dia das mesmas. Tais elementos fazem fluir a imaginação remetendo a atividade ao lúdico.

Após a aplicação do projeto de aprendizagem, questionada sobre a validade do mesmo, a professora relata da importância do mesmo para os alunos: "A boa aula de Ciências seria, sempre, com a experiência. Não achas? Por que aí você explica e mostra que não está mentindo que nem os cientistas fazem."

Tendo por base o fragmento supracitado, nota-se que, possivelmente, a concepção dessa professora deve estar atribuída a sua experiência enquanto aluna, uma vez que, na maioria das vezes, o livro didático dá ênfase à experiência como fator decisivo e fundamental para o estabelecimento do enunciado dos conceitos científicos (CARVALHO, 1992). 


\section{Compreensões do processo}

O projeto desenvolvido resultou em uma experiência na qual pôde ser verificado o potencial dos alunos dos iniciais do Ensino Fundamental em aprender conceitos relacionados à área de Ciências, através da experimentação em sala de aula, desmistificando a lógica de que a aprendizagem de tais conteúdos é de extrema complexidade para as crianças.

Embora nem sempre existam condições para se testar a hipótese de um experimento, as Novas Tecnologias da Informação e Comunicação podem auxiliar a elucidar melhor tais experimentos. A experimentação, por simulação, pode contribuir para aproximar o ensino de Ciências das características do trabalho científico, contribuindo também para a aquisição de conhecimentos e para o desenvolvimento mental dos alunos.

A experimentação se justifica por motivos ligados à estrutura da Ciência como ingrediente do ensino. Utilizar experimentos a partir das Novas Tecnologias, em especial os Objetos Virtuais de Aprendizagem como ponto de partida para desenvolver a compreensão de conceitos ou encaixá-los em um momento propício, para que os alunos percebam sua relação com as ideias discutidas em sala de aula, são as funções que devem ser exploradas na experimentação. A maneira pela qual a experimentação é utilizada trata de um papel mais importante do que a própria experimentação em si.

Com o advento das Novas Tecnologias da Informação e Comunicação na Educação, o modelo tradicional de ensino tem se tornado cada vez mais obsoleto, perdendo assim, um espaço cada vez mais considerável para o ensino no qual o aluno é mais protagonista de sua aprendizagem, característica essa principal da experimentação. O perfil dos estudantes também tem mudado; eles estão mais autossuficientes, desprendidos da figura central do professor. 


\section{Referências}

ABRÃO, Ruhena Kelber. $O$ espaço o movimento e o brincar no período de transição da Educação Infantil e o primeiro ano. 2011, 94f. Dissertação (Mestrado em Educação Física) Universidade de Pelotas.

BRASIL. Lei de diretrizes e bases da educação nacional. Brasília: Ministério da Educação, 1996.

CARVALHO, Ana Maria. Formação dos professores de ciências. São Paulo: Cortez, 1992.

CARVALHO, Ana Maria et al. Ciências no ensino fundamental: o conhecimento físico. Scipione: Cortez, 1998.

COELHO, Suzana. Maria. et al. Formação continuada de professores numa visão construtivista: Contextos didáticos, estratégias e formas de aprendizagem no ensino experimental de Física. Caderno Brasileiro de Ensino de Física, Florianópolis, v. 25, n. 1, 2008.

COLL, Cesar. Aprendizagem escolar e construção do conhecimento. Porto Alegre: Artmed, 1994.

CORRÊA, Roberta Guimarães; FERREIRA, Luiz Henrique. $O$ uso do filme didático Cavernas: sob o olhar da química com alunos de ensino médio. In: ENCONTRO NACIONAL DE ENSINO DE QUÍMICA, XIV. Anais. XIV ENCONTRO NACIONAL DE ENSINO DE QUÍMICA. Universidade Federal de São Carlos, 2008.

HODSON, Randy. Some Considerations concerning the functional form of earnings social science research, 1998.

GABEL, Dorothy. Handbook of research on science teaching and learning. New York: Simon \& Schuster Macmillan, 1993.

LÉVY, Pierre. A máquina universo: criação, cognição e cultura informática. Porto Alegre: Artmed, 2007.

MEDEIROS. Alexandre; MEDEIROS, Cleide. Possibilidades e limitações das simulações computacionais no ensino de física. Revista Brasileira de Ensino de Física, n. 24, p. 77-86, 2002.

MOREIRA, Marco Antonio. Ensino aprendizagens: enfoques teóricos. São Paulo: Moraes, 1995.

OCDE (2010). PISA 2009. Technical report. Disponível no site www.pisa.oecd.org. Acesso em 14/08/2011. 
SPINELLI, Walter. Os objetos virtuais de aprendizagem: ação, criação e conhecimento. 2009. Disponível em:

http://www.lapef.fe.usp.br/rived/textoscomplementares/textolmodulo5.pdf. Acesso em 12.01.2012.

PIAGET, Jean. Psicologia e pedagogia. Rio de Janeiro: Forense Universitária, 1995.

VALADARES, Jorge. 0 ensino experimental das Ciências: do conceito à prática: Investigação-Acção/Reflexão. Lisboa: Universidade Aberta. 2009.

YIN, Robert. Estudo de caso: planejamento e métodos. Porto Alegre: Bookman, 2001.

Universidade do Estado de Santa Catarina - UDESC

Programa de Pós-Graduação em Educação - PPGE 